\title{
Attitude of High School Students Towards Monthly Mark Ranking and Reading in the Manzini Region in Eswatini
}

\author{
Alfred Fana Tsikati ${ }^{1,}$, , Zimele Ziyane ${ }^{2}$ \\ ${ }^{1}$ Department of Agricultural Education and Extension' Faculty of Agriculture, University of Eswatini, Manzini, Eswatini \\ ${ }^{2}$ Agriculture Department, Ntfonjeni High School, Pigg's Peak, Eswatini
}

Email address:

tsikatiaf@uniswa.sz(A. F. Tsikati),ziyanezimele@gmail.com (Z.Ziyane)

${ }^{*}$ Corresponding author

\section{To cite this article:}

Alfred Fana Tsikati, Zimele Ziyane. Attitude of High School Students Towards Monthly Mark Ranking and Reading in the Manzini Region in Eswatini. International Journal of Secondary Education. Vol. 8, No. 3, 2020, pp. 82-86. doi: 10.11648/j.ijsedu.20200803.11

Received: July 9, 2019; Accepted: August 12, 2019; Published: June 23, 2020

\begin{abstract}
Most schools have mark readings or announcement in an attempt to improve students' academic performance. A paucity of studies exists on the attitudes of students towards mark ranking and announcement. Thus, the purpose of the study was to describe the attitude of students towards mark ranking and announcement of high school students in the Manzini region in Eswatini. A descriptive survey was employed; using Form 4 and Form 5 students from six schools in the Manzini region. A questionnaire reviewed by two lecturers from the Department of Agricultural Education and Extension, one from the Department of Consumer Sciences in the University of Eswatini and two high school teachers for face and content validity was used for data collection. Cronbach's alpha was used to determine the inter-item reliability of the instrument and was found to be 0.76 . Findings of the study revealed that even though mark ranking and reading enhanced performance of best students; it also humiliated and embarrassed poor performing students; causing them to withdraw from learning. Therefore, the study recommended that monthly mark announcement should be exercised with care and programmes to assist poor performing of students must be developed.
\end{abstract}

Keywords: Mark Announcement, Mark Ranking, Mark Reading, Student's Attitude, Student Marks

\section{Introduction}

In an effort to encourage students perform well academically, most schools have mark readings or announcement. Oliva and Pawlas [1] described mark announcement as an exercise whereby students are acknowledged for their effort towards school work. Teachers calculate the average from the total with the number of subjects taken. The scores are then ranked and the students' monthly ranks are compiled by expressing the average marks in percentages [2]. Mark ranking is preferred than providing grades alone as it provides a clear picture of academic aptitude or of potential for success of the learner [3].

The marks of students who excelled are announced, in the presence of their peers [1]. Some schools even announce the marks of the pupils who performed poorly. These ranked marks after announcement are then displayed on the school bulletin boards for every student to be able to see how she or he performed in that particular month [2]. The first person on the list is the best student and the last is the worst performing student [4]. In the USA, some schools require teachers to display student test scores in the classroom [5]. In Russia, the grades are not only announced, but comments are also made as the grades are announced [6].

The scores are displayed to be seen by all the students, parents, and staff [5]. Aguilar [5] further stated that the main purpose of making student's scores public is for educators, parents, and children to be motivated to work harder and be inspired throughout the year. It is about taking collective responsibility in seeing the growth of the pupils [5]. Mark publicising can reveal the strengths and weaknesses of the students and the teaching abilities of the teacher [3]. Similarly, mark ranking helps students to work harder if appearing on lower ranks and also motivate the ones appearing at the higher ranks. This feedback also enables the students to measure their achievement and understanding of the different subjects [2]. 
Mkhwanazi [7] stated that mark ranking and reading encourage students to get better marks in subsequent rankings. Top performing students view announcing of marks as positive recognition of their success and encouragement to work hard [8,9]. Wilson [10] argued that students are encouraged by getting higher grades as they view them as a positive feedback. Michikodesu and Yanakoroleva [6] stated that most pupils start to look at what the $1^{\text {st }}$ or $2^{\text {nd }}$ positioned student is doing to get good grades. Mark reading creates a healthy competition among the students. Michikodesu and Yanakoroleva [6] recommended that recognition should be given to top performing students. Masuku (2014) articulates that in classes where grades were posted, students were consistently performing higher, thus, being able to visibly see their progress; which is definitely beneficial. Michikodesu and Yanakoroleva [6] further argued that mark ranking may serve as a badge of honour for students at the top of the class.

On the other hand, Marburger [8] found that mark ranking and reading of low performing students caused them to withdraw from learning. Low performing students regarded mark ranking and reading as irrelevant, discriminatory and meaningless. Mark ranking and reading is viewed as rewards for the best performing students and as punishment to worst performing students [10]. It causes division between the intelligent students and those that do not perform well [10]. Dlamini [11] concurred that students are divided by the positions and further explained that students on lower ranks have a low self-esteem and are intimidated to even make public speeches. Wilson [10] found that some students appear on same ranks every month. Thus, some students consider monthly mark ranking and reading as a waste of time because it does not improve the work of students or effort but encourages cheating and other forms of copying [9]. Struggling students may be left feeling ashamed and the exercise may be humiliating, embarrassing, degrading and may also perpetrate bullying [6]. The Federal Law, Family Educational Rights and Privacy Act [FERPA] of 1974 in the U.S.A, prohibits the disclosures of students' performance or grade in the class with the student's parent, unless there is a written permission from the student or other provisions of the law are met [12].

In Eswatini, monthly mark reading is optional; and was started in the $21^{\text {st }}$ century. It serves as a feedback to the students and encourages students to perform better [7, 13]. Monthly mark reading for the top performing students is done during the (morning) assembly in most of the time and the complete list of the class is pinned on the notice or bulletin board [4]. Eighty-nine percent of the high schools in Eswatini prepare reports on students' academic progress monthly. Of the $89 \%, 50 \%$ announce the names of the best and worst performing students and $30 \%$ only call the best performing students. Despite the monthly mark ranking and reading of students' academic achievement, the performance of some students does not really improve, as some students are consistently at the bottom rank month after month [4]. A paucity of research has been conducted on mark ranking and reading or announcement in Eswatini. The question is "What is the attitude of students towards mark ranking and reading in Eswatini?"

\section{Purpose and Objectives of the Study}

The purpose of the study is to describe the attitude of students towards the mark ranking and announcement of the monthly test scores in Manzini high schools in Eswatini. The specific objectives of the study were to:

1. describe respondents by demographic characteristics and background information.

2. describe the students' attitudes towards the monthly announcement of marks publicly.

3. describe the students' attitudes towards the monthly ranking of test scores.

4. determine the contribution of monthly mark announcement on students' academic affairs.

5. identify preferred method of reporting students' academic performance.

\section{Methodology}

This was a descriptive survey targeting Form 4 and 5 students in the Manzini region in Eswatini. Six high schools from the Manzini region were randomly sampled and two intact classes [one Form 4 and one Form 5] were randomly sampled from each school. All the students in each intact class formed part of the study. Thus, a total of 180 students participated in the study.

A questionnaire was developed from the literature and used for data collection. A six-point numerical rating scale was used to measure the variables of the study. The Likerttype scale had the following ranges: $6=$ Strongly Agree; $5=$ Agree; 4= Slightly Agree; 3= Slightly Disagree; $2=$ Disagree and $1=$ Strongly Disagree. The questionnaire was validated by a panel of experts $(n=4)$ : one lecturer from the Department of Consumer Sciences, one lecturer from the Department of Agricultural Education and Extension at the University of Eswatini and two high school teachers from Manzini schools in Eswatini. Comments from these experts were used to modify the questionnaire. A pilot study using 30 students from schools not participating in the study was conducted. Data from the pilot study was used to establish inter-item reliability using Cronbach's Alpha in the Statistical Package for Social Sciences (SPSS) version 20. The reliability coefficient of the instrument was .76 which means the instrument was $76 \%$ reliable.

The questionnaires were personally delivered to respondents either during school free periods or lunch hour. The respondents answered the questionnaires immediately after delivery. The questionnaires were checked if there were no pages left unattended as they were collected while the respondents were still around, thus, controlling non-response error. Data were analysed using descriptive statistics such as standard deviations, means, frequencies and percentages in 
SPSS version 20.

\section{Findings and Discussion of the Study}

\subsection{Demographic Characteristics and Background Information}

Table 1 depicts that the number of males $(n=91,50.6 \%)$ and females $(n=89,49.4 \%)$ were almost equal. An overwhelming majority of the respondents were 16 years and above $(n=178,98.9 \%)$. Most of the students $(n=113,62.8 \%)$ did both their secondary and high school education in the school while 67 students $(37.2 \%)$ joined the school at the high school level. Having been with the school was important for the student in understanding the culture of the school. A majority of the respondents were coming from schools in rural areas $(n=150.83 .3 \%)$. Ninety-four of the students $(52.2 \%)$ were doing Form 5 while 86 students (47.8\%) were doing Form 4. Most of the students were average in academic performance $(n=148,82.2 \%)$. Comparatively, most students were in the top performing category $(n=29,16 \%)$ than low performing category $(n=3,1.7 \%)$.

Table 1. Demographic characteristics of respondents $(n=180)$.

\begin{tabular}{lcc}
\hline Variables & f & \% \\
\hline Sex & & \\
Female & 89 & 49.4 \\
Male & 91 & 50.6 \\
Age & & \\
Below 16 years & 2 & 1.1 \\
16 years and above & 178 & 98.9 \\
School location & & \\
Rural & 150 & 83.3 \\
Urban & 30 & 16.7 \\
Did both secondary and high school in current school & \\
Yes & 113 & 62.8 \\
No & 67 & 37.2 \\
Class & & \\
Form 4 & 86 & 47.8 \\
\hline
\end{tabular}

\begin{tabular}{lll}
\hline Variables & f & \% \\
\hline Form 5 & 94 & 52.2 \\
Monthly academic performance rank & & \\
Top performance & 29 & 16.1 \\
Average performance & 148 & 82.2 \\
Bottom performance & 3 & 1.7 \\
\hline
\end{tabular}

\subsection{Attitudes of Students Towards Monthly Mark Announcement}

Table 2 depicts that the students had mixed feelings about mark reading or announcements. On the positive note, the students considered mark reading or announcement in the following manner: best performing students are encouraged $(\mathrm{M}=5.18, \mathrm{SD}=1.44)$; better performing students help those who struggle to do well $(\mathrm{M}=4.56, \mathrm{SD}=1.88)$; and calling out marks creates a healthy competition among the students $(\mathrm{M}=4.12, \mathrm{SD}=1.85)$. On the negative note, the students considered mark reading or announcement in the following manner: calling out names of poor performing students is humiliating and embarrassing $(\mathrm{M}=4.83, \mathrm{SD}=1.65)$; teachers make a lot of mistakes when calculating the marks, thus, the whole exercise is inaccurate $(\mathrm{M}=4.22, \mathrm{SD}=1.72)$; lead to some students absenting themselves on the day the marks are announced $(\mathrm{M}=4.16, \mathrm{SD}=1.89)$; teachers may label students based on the mark reading $(\mathrm{M}=3.89, \mathrm{SD}=1.95)$ and announcing student's performance creates a division between the best and worst performing students $(\mathrm{M}=3.86, \mathrm{SD}=2.03)$.

The findings are consistence with those of Mkhwanazi [7]. Mkhwanazi [7] reported that better performing students get encouraged by being mentioned among the best in the school. Similarly, Dlamini [11] and Mwawenda [3] found that mark announcement could be used as way of giving both teachers and students feedback on their progress. However, Dlamini [11] and Masuku [14] reported that mark announcement divided the students based on whether they are at the top or bottom. Marburger [8] further articulated that mark reading caused low performing students to withdraw from learning.

Table 2. Attitudes of students towards monthly mark announcement $(n=180)$.

\begin{tabular}{lll}
\hline Statement & M & S D \\
\hline Best performing students are encouraged & 5.18 \\
Calling out names of poor performing students is humiliating and embarrassing & 4.83 \\
Announcing students' performance is way of providing feedback to students & 4.68 \\
Better performing students help those who struggle to do well & 4.56 & 1.44 \\
Erroneous as teachers make a lot of mistakes when calculating the marks & 4.22 & 4.16 \\
Lead to some students absenting themselves on the day the marks are announced & 4.12 \\
Mark announcement creates a healthy competition & 3.89 & 1.83 \\
Teachers label students based on the mark reading & 3.86 & 1.88 \\
Mark announcement creates a division between the best and worst performing students & 3.46 \\
It is best to announce both the students who did well and those who performed badly & 1.72 \\
Overall & 1.89 \\
\hline
\end{tabular}

6= Strongly Agree; 5=Agree; 4= Slightly Agree; 3= Slightly Disagree; $2=$ Disagree and 1= Strongly Disagree

\subsection{Attitudes of Students Towards Ranking}

Table 3 depicts that generally the students had a positive attitude about the ranking of marks before they are announced. The students viewed mark ranking in the following manner: mark rankings used to measure if students qualify for further education such as admission to tertiary education $(\mathrm{M}=5.34, \mathrm{SD}=1.13)$; encourages best performing students to work hard $\quad(\mathrm{M}=5.18, \mathrm{SD}=1.44)$; and channels students to certain career choices $(\mathrm{M}=5.04, \mathrm{SD}=1.31)$. Contrary, students' viewed mark ranking in the following manner: puts more emphasis on getting high grades rather than to learn and understand $(\mathrm{M}=4.74, \mathrm{SD}=1.47)$; grades 
having not been ranked do not provide clear feedback to the learners $(\mathrm{M}=4.72, \mathrm{SD}=1.38)$; teachers may treat students according to their ranking $(\mathrm{M}=3.89, \mathrm{SD}=1.95)$; ranking marks creates division between top and low ranked students $(\mathrm{M}=3.87, \mathrm{SD}=1.85)$; low ranked students withdraw from learning as they get discouraged $(\mathrm{M}=3.84, \mathrm{SD}=1.97)$ and ranking marks spoil teacher-student relationship as low ranked students blame teachers $(\mathrm{M}=3.76, \mathrm{SD}=1.86)$. The findings of the study are consistent with Mwawenda [3]'s assertion that mark ranking indicates if a student qualifies for college or university. Top performing students consider mark ranking as recognition of their success and encouragement to work hard [8, 9]. However, Kohn [15] stated that mark ranking makes students focus more on getting higher grades than learning and understanding. Furthermore, students on lower ranks tend to have a low self-esteem [11] and withdraw from learning [8].

Table 3. Attitudes of students towards ranking $(n=180)$.

\begin{tabular}{lll}
\hline Statement & M D & \\
\hline Mark rankings measures if students qualify for tertiary education & 5.34 \\
Ranked marks encourage best performing students & 5.18 & 1.13 \\
Mark ranking channels students for career choices & 5.04 & 4.44 \\
Ranking marks puts more emphasis on getting high grades rather than to learn and understand & 1.31 & 4.74 \\
Grades having not been ranked do not provide clear feedback to the learners & 4.72 & 3.89 \\
Teachers may treat students according to their ranking & 3.87 \\
Ranking marks creates division between top and low ranked students & 3.84 \\
Low ranked students withdraw from learning as they get discouraged & 1.38 \\
Ranks spoil teacher-student relationship as low ranked students blame teachers & 1.95 \\
Ranking of marks reduces teaching and learning time allocated & 1.85 \\
Aggregate scores should be based only in passed subjects & 1.97 \\
Most students appear on the same ranks every month & 1.76 \\
Overall & 1.96 \\
\hline
\end{tabular}

6= Strongly Agree; $5=$ Agree; $4=$ Slightly Agree; $3=$ Slightly Disagree; $2=$ Disagree and 1= Strongly Disagree

\subsection{Contribution of Monthly Mark Announcement or Reading to Students}

Table 4 reveals that all the items were contributing positively to the students' academic affairs $(\mathrm{M}=4.76$, $\mathrm{SD}=1.53$ ). The monthly mark reading was contributing in the following order: makes students study very hard before writing tests $(\mathrm{M}=5.56, \mathrm{SD}=0.98)$; communicates student's improvement $(\mathrm{M}=4.84, \mathrm{SD}=1.48)$, serves as a better way of disciplining students than corporal punishment $(\mathrm{M}=4.70$, $\mathrm{SD}=1.66)$; and increases students' self-esteem $(\mathrm{M}=4.66$,
$\mathrm{SD}=1.61$ ). These findings are consistent with Mwawenda [3]'s argument that mark announcement highlights the strengths and weaknesses of the students. Similarly, mark ranking helps students to put more effort if appearing on lower ranks and motivates the one appearing in the higher ranks. This feedback also enables the students to measure their achievement and understanding of the different subjects [2]. Mark announcement makes students focus more on getting higher grades than learning and understanding [15].

Table 4. Role of monthly mark announcement $(n=180)$.

\begin{tabular}{lll}
\hline Statement & M & S D \\
\hline Makes students to study very hard before writing tests & 5.56 & 0.98 \\
Communicates student's improvement & 4.84 & 1.48 \\
A better way of disciplining students than corporal punishment & 4.70 & 1.66 \\
Increases students' self-esteem & 4.66 & 1.61 \\
Overall & 4.76 \\
\hline
\end{tabular}

6=Strongly Agree; 5= Agree; 4= Slightly Agree; 3= Slightly Disagree; $2=$ Disagree and 1= Strongly Disagree

\subsection{Appropriate Methods of Reporting Student's Performance}

Table 5 depicts that students preferred that their marks should be reported during the Speech and Prize Day $(\mathrm{M}=5.25, \mathrm{SD}=1.34)$ and the formal reports issued termly $(\mathrm{M}=5.02, \mathrm{SD}=1.42)$. It can be observed that they do not want their mark to be announced monthly $(\mathrm{M}=3.46, \mathrm{SD}=2.08)$.
Also, students do not like when their marks are pinned on the bulletin boards $(\mathrm{M}=3.29, \mathrm{SD}=2.11)$. Wilson [10] stated that students prefer formal report cards than monthly ranks. This is because students view monthly ranks as rewards for the best performing students and as punishment to worst performing students.

Table 5. Appropriate methods of reporting students' performance $(n=180)$.

\begin{tabular}{llll}
\hline Statement & M & \\
\hline Speech and prize day every year & 5.25 & S D \\
Formal reports every end of school term & 5.02 & 1.34 \\
Mark reading or announcement monthly & 3.46 & 1.42 \\
\hline
\end{tabular}




\begin{tabular}{lll}
\hline Statement & M & S D \\
\hline Use of sitting arrangement rather than calling out of students marks & 4.34 & 1.88 \\
Open day every year & 3.83 & 1.96 \\
Pinning of students test scores on school bulletin boards & 3.29 & 2.11 \\
\hline
\end{tabular}

6= Strongly Agree; $5=$ Agree; $4=$ Slightly Agree; $3=$ Slightly Disagree; $2=$ Disagree and $1=$ Strongly Disagree

\section{Conclusions and Recommendations}

The study concluded that the students had a positive attitude towards monthly mark announcement or reading as it encourages best performing students to work hard; disclose struggling students so that they are assisted by their colleagues; and create a healthy competition among the students. Another conclusion drawn was that students' negative attitude emanated from the fact that monthly mark announcement or reading humiliates and embarrasses poor performing students; grades are at times miscalculated; leads to teachers labelling students as good and bad; thus, causing divisions among them. Mark ranking was considered important for students to gauge themselves if they can be admitted for intended programmes in institutions of higher education. Mark ranking can also make students to focus on getting high grades, thus, encouraging undesirable practices such as copying and memorising instead of understanding. Lowly ranked students may withdraw from learning and the relationship with their teachers may be compromised. Students do not want monthly mark reading but prefer their academic performance to be communicated during Speech and Prize Giving Day, and termly reports.

\section{Recommendations for Action}

From the findings of the study, the following recommendations were made:

1. School administration should clearly explain the objectives of monthly mark reading or announcement to both the staff and students.

2. Schools should exercise mark announcement or reading cautiously as it can make or break the students.

3. Schools should have programmes to assist the low performing students after each mark reading or announcement.

4. Teachers should carefully compute the students' grades as they have implications on students' reputation.

5. Teachers should not label students on the basis of academic performance.

6. Students should focus on understanding concepts than scoring high grades which lead to copying and memorising.

7. The relationship between teachers and students should not be founded on marks because student performance is unpredictable.

\section{Acknowledgements}

The authors are indebted to the schools and students for participating in this study. Special accolades are also due to
Mr. E. M. Manana for the tireless effort in proofreading and editing this article.

\section{References}

[1] P. F. Oliva and G. E. Palwas, "Supervision for today's schools". (7th ed.). Wiley Pub. inc, 2004.

[2] D. Durden and D. Ellis, "The effects of attendance on student learning in Principles of Economic". American Economic Review Papers and Proceedings, 1995.

[3] T. S. Mwawenda, "Educational Psychology: An African perspective", ( $3^{\text {rd }}$ Ed.). Pub. Heinemann, 2004.

[4] B. Dlamini, B, "Perceptions of students towards monthly ranks at schools in the Shiselweni region" (Unpublished B.Sc. Research Project Report). University of Swaziland, Kwaluseni, 2009.

[5] E. Aguilar, "Is it Okay to Display Student Testing Data in Classrooms?" 2011. Retrieved from: http://www.edutopia.org

[6] L. E. B, Michikodesu and B. Yanakoroleva, "Public posting of test scores Motivation or humiliation?2014. Retrieved from http://blogs.babycenter.com

[7] L. Mkhwanazi (2005). "Towards better teaching" (Unpublished B.Sc.). Research Project Report. University of Swaziland, Luyengo, 2005.

[8] D. Marburger, "Absenteeism and Undergraduate Exam Performance.”, Journal of Economic Education, 2001.

[9] A. Johnson and G. Johnson, G. (1989). "Cooperation and Competition: Theory and Research." Edina: Minn Interaction Book Company, 1989.

[10] Wilson, D. (1999). Grades, diplomas and transcripts for students with disabilities. Retrieved from: http://www.wil.studebtsdisa.html.

[11] Dlamini, B. (2004). Uses of monthly ranks in schools: A case study in the Shiselweni region (Unpublished B.Sc. Research Project Report). University of Swaziland, Kwaluseni.

[12] Family Educational Rights and Privacy Act [FERPA] (1974). Retrieved from http://www2.ed.gov

[13] Ministry of Education and Training. (2007). Grading Polices in Schools. http://www.swazi.child.edu/ppe

[14] S. Masuku (2014). Perceptions of high school students on their monthly performance rank announcements in the Shiselweni Region. Unpublished B.Sc. Research Project Report. University of Swaziland, Luyengo.

[15] Kohn, A. (1992). No contest: The case against competition (Rev. Ed.). Boston: Houghton Mifflin. 